\title{
Ethanol-induced autonomic responses and risk taking increase in young adults with a positive family history of alcohol problems
}

\author{
Florencia Caneto ${ }^{\mathrm{a}}$, Ricardo Marcos Pautassi ${ }^{\mathrm{b}, \mathrm{c}}$, Angelina Pilatti ${ }^{\mathrm{a}, *}$ \\ a CIPSI Grupo Vinculado CIECS-UNC-CONICET, Universidad Nacional de Córdoba, Argentina \\ b Instituto de Investigación Médica M. y M. Ferreyra, INIMEC-CONICET, Universidad Nacional de Córdoba, Córdoba C.P. 5000, Argentina \\ c Facultad de Psicología, Universidad Nacional de Córdoba, Córdoba C.P. 5000, Argentina
}

\section{H I G H L I G H T S}

- Alcohol's effects were tested in persons with a family history of alcohol problems.

- These subjects exhibited increased alcohol-induced heart rate and risk taking.

- These subjects were insensitive to the subjective effects of alcohol.

- Alcohol did not have an effect on the perception of time.

- These responses may mediate the effects of a family history of alcohol problems.

\section{A R T I C L E I N F O}

\section{Keywords:}

Family history of alcohol

Impulsivity

Risk taking

Heart rate

Alcohol

\begin{abstract}
A B S T R A C T
The mechanisms that underlie the greater prevalence of alcohol use disorders in individuals with a positive family history $(\mathrm{FH}+)$ of alcohol abuse are still under investigation. These subjects may exhibit differential sensitivity to alcohol's effects on psychomotor stimulation and impulsivity. Alcohol-induced psychomotor stimulation, measured as the heart rate (HR) response, is a proxy for the positive rewarding effects of the drug. We analyzed alcohol-induced effects on time perception (Time Production Task), risk taking (Balloon Analogue Risk Task [BART]), and HR in FH + and FH - participants. In the $\mathrm{FH}+$ and $\mathrm{FH}-$ groups, women and men received 0.6 and $0.7 \mathrm{~g} / \mathrm{kg}$ alcohol, respectively. The alcohol dose yielded a breath alcohol concentration of $0.08 \%$ throughout the experiment. The control groups received placebo, and the subjective perception of alcohol intoxication was assessed. Alcohol intoxication significantly increased HR and the adjusted average number of pumps on the BART (a measure of risk taking) in $\mathrm{FH}+$ men and women but not in $\mathrm{FH}-$ participants. Behavioral impulsivity was unaffected by alcohol or a FH of alcohol abuse. $\mathrm{FH}$ - but not $\mathrm{FH}+$ participants who received alcohol reported significantly greater subjective perception of alcohol's effects than their placebo counterparts. These results indicate that $\mathrm{FH}+$ individuals presented heightened sensitivity to alcohol-induced HR stimulation and alcohol-induced risk taking compared with their FH - counterparts. FH + subjects, however, were insensitive to the subjective effects of alcohol. This idiosyncratic response pattern may be a likely pathway by which a FH of alcohol problems promotes alcohol drinking.
\end{abstract}

\section{Introduction}

A positive family history $(\mathrm{FH}+)$ of alcohol abuse is a risk factor for alcohol use disorders (AUDs; LaBrie, Migliuri, Kenney, \& Lac, 2010). FH + college students exhibit more alcohol use and more alcohol-related problems (LaBrie et al., 2010) than peers without a family history (FH -) of alcohol abuse. Previous work reported synergistic effects of $\mathrm{FH}+$ and other risk factors on AUDs (Jenkins et al., 2011; Pilatti, Caneto, Garimaldi, Vera, \& Pautassi, 2014).
The mechanisms that underlie the greater risk of AUD that is exhibited by FH + subjects have been elusive. $\mathrm{FH}+$ may decrease the age of onset of alcohol use (Dawson, 2000) or alter the sensitivity to alcohol-induced psychomotor stimulation or impulsivity (Kareken et al., 2013). Impulsivity is a broad theoretical construct that encompasses a wide range of behaviors, including delay intolerance (Dalley, Everitt, \& Robbins, 2011), poor inhibitory control (Potenza \& de Wit, 2010), and unplanned behavior (Smith et al., 2007). Greater impulsivity has been associated with drug use and drug addiction (de Wit,

\footnotetext{
* Corresponding author at: Facultad de Psicología, Enrique Barros y Enfermera Gordillo s/n, Ciudad Universitaria, Córdoba C.P. 5000, Argentina

E-mail address: angepilatti@gmail.com (A. Pilatti).
} 
2009), and alcohol and drug use can alter impulsive behavior (Dalley et al., 2011; de Wit, 2009). Each dimension of impulsivity is differentially associated with different aspects of substance use. For example, acting rashly under a strong positive or negative mood is significantly associated with alcohol-related problems, and a lack of perseverance is strongly related to drinking quantity (Coskunpinar, Dir, \& Cyders, 2013). Acute alcohol intoxication also differentially impacts each dimension of this multidimensional construct. For example, acute alcohol ingestion dose-dependently affects motor but not reflective impulsivity (Caswell, Morgan, \& Duka, 2013; Rose \& Duka, 2008). Time perception and risk taking are two processes that are related to impulsivity. Impulsive individuals exhibit abnormal timing functioning (Baumann \& Odum, 2012; Dougherty et al., 2007; Rubia, Halari, Christakou, \& Taylor, 2009) and greater behavioral risk taking in the Balloon Analogue Risk Task (BART; Cyders et al., 2010; Pilatti, Fernández, Viola, García, \& Pautassi, 2017).

$\mathrm{FH}+$ individuals presented more impulsivity on measures of response initiation and response inhibition (Acheson, Richard, Mathias, \& Dougherty, 2011) and lower tolerance to delayed reward (Herting, Schwartz, Mitchell, \& Nagel, 2010) compared with FH - individuals. However, $\mathrm{FH}+$ individuals appear to be less sensitive to the acute augmenting effects of alcohol on motor impulsivity in the stop signal task (Kareken et al., 2013). These results are consistent with the Low Level of Response Model. A low level of response to alcohol may promote alcohol initiation or escalation (Quinn \& Fromme, 2011; Schuckit, 1985; Schuckit et al., 2000; Schuckit \& Gold, 1988) by facilitating binge drinking as a means to reach a desired level of intoxication (Schuckit, 2009). Some evidence indicates that FH + subjects exhibit enhanced sensitivity to the psychostimulant effects of alcohol, as measured by heart rate (HR; Conrod, Peterson, Pihl, \& Mankowski, 1997; Conrod, Peterson, \& Pihl, 2001). Ethanol-induced psychomotor stimulation has been considered a proxy for the positive rewarding effects of the drug, which in turn promote alcohol seeking and intake (Assaad et al., 2006). In one of these studies (Conrod et al., 1997), FH + participants exhibited a significantly greater elevation of HR after moderate, acute alcohol intoxication $(0.8 \mathrm{~g} / \mathrm{kg})$ during the rising limb of the blood alcohol concentration (BAC) curve compared with $\mathrm{FH}-$ controls.

The present study investigated alcohol-induced ( 0.6 and $0.7 \mathrm{~g} / \mathrm{kg}$, women and men, respectively) effects on time perception, risk taking, and $\mathrm{HR}$ in $\mathrm{FH}+$ and $\mathrm{FH}-$ participants. The subjective perception of alcohol intoxication was also assessed. Our hypothesis was that $\mathrm{FH}+$ participants would exhibit significantly greater alcohol-induced elevations of HR (Conrod et al., 1997) and alcohol-induced risk-taking behavior on the BART but significantly less alcohol-induced impulsivity on the Time Production Task (TIME) compared with their FH - counterparts. Unknown were the expected effects on time perception. Rose and Grunsell (2008) reported nonsignificant effects of acute alcohol intoxication on time perception in social and heavy episodic drinkers.

Tolerance to ethanol can be measured at several levels of analysis. Researchers can measure the initial response to the objective consequences of alcohol intoxication, such as alcohol-induced hypothermia, and the development of adaptations across the blood alcohol concentration (BAC) curve (Pautassi, Godoy, \& Molina, 2015). In the present study, we focused on the self-reported subjective perception of intoxication. We expected differences between $\mathrm{FH}+$ and $\mathrm{FH}-$ subjects, although the direction of this difference was difficult to predict. Pilatti et al. (2014) found a lower prevalence of drunkenness in FH + subjects than in $\mathrm{FH}$ - subjects, suggesting the development of tolerance in the $\mathrm{FH}+$ group. Based on this and other findings (Schuckit, Smith, \& Kalmijn, 2004), we could expect a lower subjective perception of intoxication in $\mathrm{FH}+$ participants. Other studies, however, reported that $\mathrm{FH}+$ subjects were more sensitive to the subjective perception of alcohol intoxication than $\mathrm{FH}-$ their counterparts (Morzorati, Ramchandani, Flury, Li, \& O'Connor, 2002).

\section{Material and methods}

\subsection{Experimental design}

A 2 (family history: $\mathrm{FH}+$ and $\mathrm{FH}-$ ) $\times 2$ (treatment: alcohol and placebo) factorial design was used. Each group was composed of 11-14 participants, with a similar distribution of men and women. Across variables, scores were obtained before and after the beverage treatment (i.e., pre- and post-drink measurements).

\subsection{Sample recruitment and screening}

The participants, 18-30 years old, were recruited from the general community in Córdoba, Argentina, through advertisements on social networks and e-mail lists that asked for volunteers for an alcohol study. The advertisement warned about the possibility of receiving an alcoholic beverage. Only individuals who were current drinkers were allowed to participate in the study. Individuals who were interested in participating completed a telephone screening and were included if they reported at least one drinking episode of 56 or $70 \mathrm{~g}$ of alcohol (women and men, respectively) within the last month (i.e., a pattern that is likely to yield a breath alcohol concentration (BrAC) of $0.08 \%$ (equivalent to the BrAC that would be induced by the alcoholic beverage that was administered during the study). They were excluded if they reported psychiatric, neurological, or cardiac conditions, ongoing treatment for an alcohol-related disorder, current consumption of psychopharmacological medication, or other serious medical conditions. Alcohol drinking was measured using an instrument that was similar to the one described by Pilatti et al. (2014). The participants were classified as $\mathrm{FH}+$ if they indicated that a biological relative (i.e., mother, father, grandmother, grandfather, uncle, aunt, brother, or sister) currently had or previously had a significant problem with alcohol drinking (i.e., a problem that led to or could lead to treatment; LaBrie et al., 2010; Pilatti et al., 2014). The other participants were classified as $\mathrm{FH}-$.

The participants were informed about the possibility of receiving an alcoholic beverage and that two vouchers to purchase books would be raffled. Participants who met the inclusion criteria were scheduled to arrive at the laboratory. They were instructed to abstain from using alcohol or illegal substances $24 \mathrm{~h}$ prior to the study and abstain from using tobacco and caffeine products and eating food $2-3 \mathrm{~h}$ before the study (depending on whether the experiment was scheduled before or after lunch, respectively).

The final sample was composed of 51 participants (mean age $=22.98 \pm 3.36$ years). The participants had drunk at least $70 \mathrm{~g}$ alcohol per occasion, twice per month. Drinking quantity and frequency (for their first and second most preferred beverages) and frequency of binge drinking and heavy episodic drinking in each group are shown in Table 1.

\subsection{Experimental procedures}

We provide a brief description of the procedures, which are graphically depicted in the timeline in Fig. 1. The tasks and instruments that were used are described in detail below. All of the procedures followed the Declaration of Helsinki and were approved by the Institutional Ethics Committee.

Each participant was individually tested in a session that lasted approximately $120 \mathrm{~min}$. The test room had a desk, chair, and laptop where the participants completed the tasks and questionnaires. The beverages were prepared in another adjacent room by an unblinded research staff member. Informed consent was obtained from the participants when they arrived at the laboratory after a debriefing that included (for women only) advice on the deleterious effects of alcohol during pregnancy and questions about the possibility of pregnancy. 
Table 1

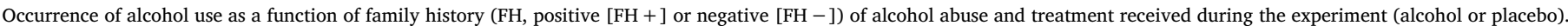

\begin{tabular}{|c|c|c|c|c|}
\hline & \multicolumn{2}{|l|}{$\mathrm{FH}+$} & \multicolumn{2}{|l|}{$\mathrm{FH}-$} \\
\hline & Alcohol $(N=11)$ & Placebo $(N=12)$ & $\operatorname{Alcohol}(N=14)$ & $\operatorname{Placebo}(N=14)$ \\
\hline \multicolumn{5}{|l|}{ Quantity of drinking (grams) } \\
\hline Preferred beverage & $75.17(\mathrm{SE}=45.41)$ & $40.89(\mathrm{SE}=19.80)$ & $73.41(\mathrm{SE}=45.99)$ & $85.90(\mathrm{SE}=53.83)$ \\
\hline 2nd preferred beverage & $71.90(\mathrm{SE}=36.76)$ & $57.57(\mathrm{SE}=45.20)$ & $66.04(\mathrm{SE}=45.10)$ & $46.96(\mathrm{SE}=27.50)$ \\
\hline Grams per occasion & $140.07(\mathrm{SE}=72.37)$ & $76.34(\mathrm{SE}=49.91)$ & $127.51(\mathrm{SE}=80.45)$ & $122.99(\mathrm{SE}=72.47)$ \\
\hline \multicolumn{5}{|l|}{ Drinking frequency } \\
\hline \multicolumn{5}{|l|}{ Last month drinking } \\
\hline Preferred beverage & $5.55(\mathrm{SE}=4.20)$ & $3.92(\mathrm{SE}=3.61)$ & $3.26(\mathrm{SE}=1.80)$ & $5.55(\mathrm{SE}=6.04)$ \\
\hline 2nd preferred beverage & $3.52(\mathrm{SE}=3.00)$ & $2.65(\mathrm{SE}=2.71)$ & $1.99(\mathrm{SE}=2.11)$ & $2.53(\mathrm{SE}=1.99)$ \\
\hline \multicolumn{5}{|l|}{ Last 6 month hazardous alcohol use } \\
\hline Binge frequency & $1.67(\mathrm{SE}=1.31)$ & $1.65(\mathrm{SE}=3.31)$ & $1.53(\mathrm{SE}=1.53)$ & $1.91(\mathrm{SE}=1.32)$ \\
\hline Heavy episodic drinking frequency & $2.88(\mathrm{SE}=2.10)$ & $2.62(\mathrm{SE}=4.38)$ & $2.79(\mathrm{SE}=2.47)$ & $3.50(\mathrm{SE}=2.21)$ \\
\hline
\end{tabular}

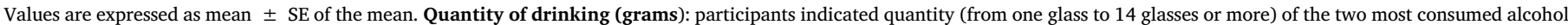

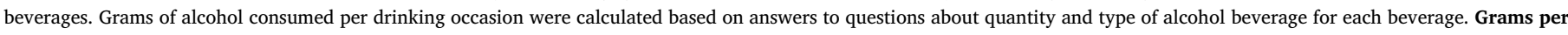

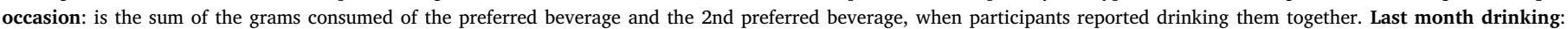

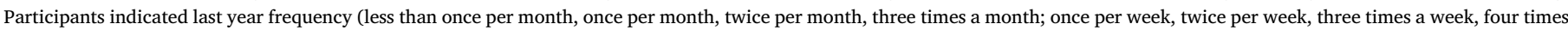

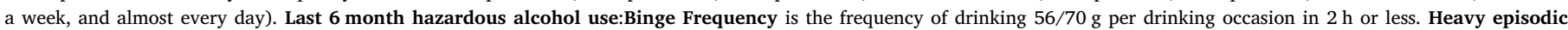
drinking frequency is the frequency of drinking 56/70 g per drinking occasion.

\subsubsection{Pre-drink phase (Fig. 1A)}

After signing the informed consent, the participants provided the first breath sample (Driveguard R110 alcoholmeter, Trisco Technology, Taiwan, China) to ensure that their BrAC was zero (Fig. 1, experimental time $0 \mathrm{~min}$ ). The participants were weighed and then seated $0.5 \mathrm{~m}$ distance from the laptop screen. Two electrodes were attached to the upper right and left sides of the chest. Two other electrodes were attached to the lower left and right legs. The electrodes collected information that was used to calculate HR across the study. The participants then completed the BART and TIME (Fig. 1, experimental times 20 and $40 \mathrm{~min}$, respectively; see below for a full description of the instruments) after receiving appropriate instructions about how to complete the tasks. Heart rate was monitored during each task.

\subsubsection{Treatment (drink) phase (Fig. 1B)}

Alcohol administration was conducted at experimental time $50 \mathrm{~min}$. The first post-drink HR measurement was recorded at that moment. Ten minutes after alcohol or placebo was ingested, the participants rinsed their mouth with water. Shortly afterward, at experimental time 65 min, a new HR measurement (HR post-drink measurement 2) was conducted. At experimental time $75 \mathrm{~min}$, the participants completed the Brief Biphasic Alcohol Effects Scale (B-BAES; Schrieks et al., 2014), and a new BrAC measurement was obtained.

\subsubsection{Post-drink phase (Fig. 1C)}

The participants completed the BART and TIME at experimental times 80 and $110 \mathrm{~min}$, respectively. Shortly after each task, they provided a breath sample and completed the B-BAES (BrAC measurements
2 and 4 and B-BAES measurements 2 and 4 at experimental times 100 and $115 \mathrm{~min}$, respectively). BrAC measurement 3 and B-BAES measurement 3 took place at experimental time $105 \mathrm{~min}$. During the postdrink phase, HR was measured at experimental times 80 and $110 \mathrm{~min}$.

After completing the final task and breathalyzer reading (which occurred at approximately $40 \mathrm{~min}$ post-drink), the participants in the placebo condition were debriefed and dismissed from the study. The participants in the alcohol condition were allowed to leave the study when their BrAC dropped to 0.03-0.04\% (Abroms, Gottlob, \& Fillmore, 2006; George, Rogers, \& Duka, 2005).

\subsection{Alcoholic beverage preparation and administration}

Alcohol doses of 0.6 and $0.7 \mathrm{~g} / \mathrm{kg}$ were used for women and men, respectively. These doses are expected to yield a BrAC of $0.08 \%$ (Cronce \& Corbin, 2010). The beverage was prepared using 96\% ethyl alcohol (Porta Hnos, Cordoba, Argentina) that was mixed in orange juice and grenadine (1:4 proportion; alcohol, vehicle). Two equal drinks were given, separated by $5-7 \mathrm{~min}$. The placebo beverage contained orange juice and grenadine only, with a few drops of alcohol and flat tonic water. Two drops of rum were sprayed on the rim of the cup to enhance the external validity and credibility of the placebo. To determine whether the blinding was successful, 25 min after drinking the beverage, the participants were asked, "How much alcohol do you think the beverage contained?" The participants answered using a visual analogue scale: 0 ("nothing at all") to 10 ("quite a lot"). The placebo beverage was effective. Among the participants who received placebo, $96 \%$ indicated that they received alcohol. Only one participant reported

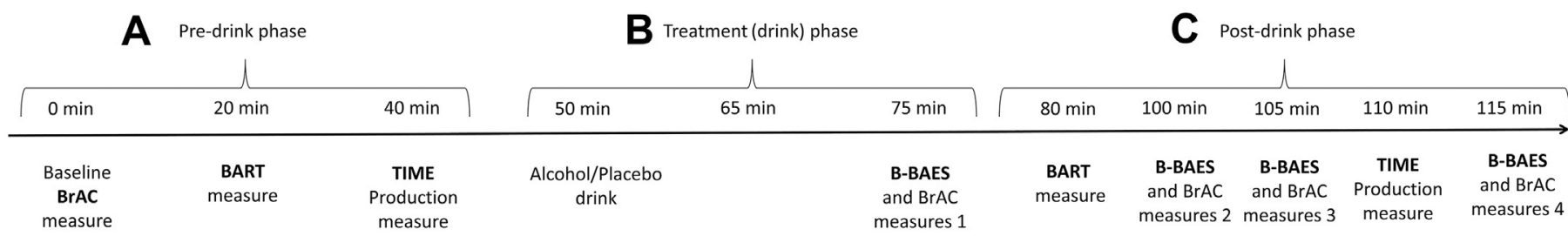

\begin{tabular}{|c|c|c|c|c|c|c|}
\hline $\begin{array}{l}\text { Basal HR } \\
\text { Measurment }\end{array}$ & $\begin{array}{c}\text { HR } \\
\text { Measurment }\end{array}$ & $\begin{array}{c}\text { HR } \\
\text { Measurment }\end{array}$ & $\begin{array}{l}\text { HR Post Drink } \\
\text { Measure } 1\end{array}$ & $\begin{array}{l}\text { HR Post Drink } \\
\text { Measure } 2\end{array}$ & $\begin{array}{c}\text { HR Post Drink } \\
\text { Measure } 3\end{array}$ & $\begin{array}{c}\text { HR Post Drink } \\
\text { Measure } 4\end{array}$ \\
\hline
\end{tabular}

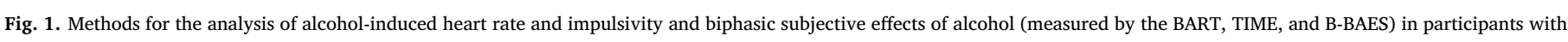

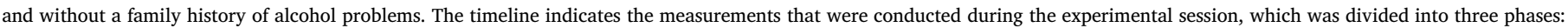

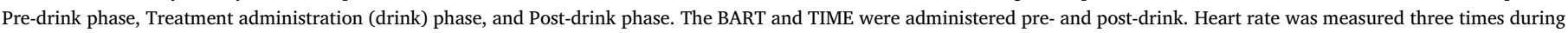
the pre-drink phase, twice during the administration phase, and twice during the post-drink phase. The B-BAES was applied four times. 
Table 2

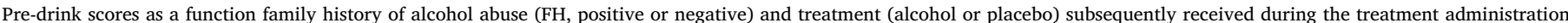
(drink) phase.

\begin{tabular}{|c|c|c|c|c|}
\hline & \multicolumn{2}{|l|}{$\mathrm{FH}+$} & \multicolumn{2}{|l|}{$\mathrm{FH}-$} \\
\hline & Alcohol $(N=11)$ & Placebo $(N=12)$ & Alcohol $(N=14)$ & Placebo $(N=14)$ \\
\hline \multicolumn{5}{|l|}{ Heart rate } \\
\hline Baseline measurement & $114.45(\mathrm{SE}=33.62)$ & $112.92(\mathrm{SE}=45.61)$ & $100.86(\mathrm{SE}=27.46)$ & $112.64(\mathrm{SE}=39.64)$ \\
\hline BART measurement & $101.80(\mathrm{SE}=39.53)$ & $119.10(\mathrm{SE}=23.75)$ & $111.88(\mathrm{SE}=20.88)$ & $119.29(\mathrm{SE}=21.79)$ \\
\hline Time measurement & $103.73(\mathrm{SE}=39.53)$ & $121.17(\mathrm{SE}=32.38)$ & $117.79(\mathrm{SE}=33.10)$ & $116.15(\mathrm{SE}=44.30)$ \\
\hline \multicolumn{5}{|l|}{ BART test } \\
\hline Adjusted average of pumps & $30.10(\mathrm{SE}=13.36)$ & $37.06(\mathrm{SE}=14.14)$ & $29.14(\mathrm{SE}=11.07)$ & $32.14(\mathrm{SE}=8.80)$ \\
\hline Total pumps & $830.09(\mathrm{SE}=331.28)$ & $9.91(\mathrm{SE}=3.34)$ & $7.43(\mathrm{SE}=3.18)$ & $8.55(\mathrm{SE}=2.77)$ \\
\hline Number of exploded balloons & $8.27(\mathrm{SE}=4.27)$ & $1013.75(\mathrm{SE}=296.22)$ & $825.43(\mathrm{SE}=274.75)$ & $909.43(\mathrm{SE}=219.97)$ \\
\hline \multicolumn{5}{|l|}{ Time production } \\
\hline 1st trial & $53.51(\mathrm{SE}=15.07)$ & $61.60(\mathrm{SE}=16.24)$ & $66.14(\mathrm{SE}=18.23)$ & $60.70(\mathrm{SE}=19.56)$ \\
\hline 2nd trial & $56.76(\mathrm{SE}=10.59)$ & $57.68(\mathrm{SE}=13.51)$ & $60.54(\mathrm{SE}=11.98)$ & $57.54(\mathrm{SE}=9.63)$ \\
\hline 3rd trial & $55.53(\mathrm{SE}=12.33)$ & $55.24(\mathrm{SE}=8.77)$ & $58.87(\mathrm{SE}=7.20)$ & $56.13(\mathrm{SE}=7.29)$ \\
\hline 4th trial & $57.59(\mathrm{SE}=16.01)$ & $60.76(\mathrm{SE}=6.77)$ & $62.49(\mathrm{SE}=8.83)$ & $54.55(\mathrm{SE}=7.29)$ \\
\hline 5th trial & $56.31(\mathrm{SE}=13.62)$ & $59.80(\mathrm{SE}=5.60)$ & $58.75(\mathrm{SE}=10.82)$ & $58.27(\mathrm{SE}=4.59)$ \\
\hline Trait impulsivity (UPPS-P) & $123.36(\mathrm{SE}=17.09)$ & $111.33(\mathrm{SE}=17.45)$ & $111.07(\mathrm{SE}=13.76)$ & $120.93(\mathrm{SE}=18.32)$ \\
\hline Negative urgency & $28.82(\mathrm{SE}=5.25)$ & $25.50(\mathrm{SE}=5.45)$ & $26.71(\mathrm{SE}=8.16)$ & $28.71(\mathrm{SE}=6.60)$ \\
\hline Lack of perseverance & $19.82(\mathrm{SE}=4.69)$ & $19.33(\mathrm{SE}=7.22)$ & $18.50(\mathrm{SE}=3.72)$ & $19.57(\mathrm{SE}=4.96)$ \\
\hline Lack of premeditation & $21.37(\mathrm{SE}=5.52)$ & $19.58(\mathrm{SE}=5.47)$ & $18.07(\mathrm{SE}=4.62)$ & $28.14(\mathrm{SE}=7.11)$ \\
\hline Sensation seeking & $32.18(\mathrm{SE}=6.51)$ & $29.50(\mathrm{SE}=6.68)$ & $29.14(\mathrm{SE}=8.54)$ & $28.14(\mathrm{SE}=7.11)$ \\
\hline Positive urgency & $25.91(\mathrm{SE}=6.47)$ & $21.58(\mathrm{SE}=4.96)$ & $22.36(\mathrm{SE}=5.42)$ & $26.57(\mathrm{SE}=8.29)$ \\
\hline
\end{tabular}

Values are expressed as mean and SE of the mean.

" 0 " on the visual analogue scale, whereas $62 \%$ of the participants reported $\geq 3$.

\subsection{Balloon analogue risk task}

The BART is a computerized task that assesses risk taking during decision making (Lejuez et al., 2007). Participants balance the potential for reward and harm (i.e., earning and losing points, respectively) across 30 trials, in which they are asked to pump a balloon by clicking the spacebar. Each click provides 5 points that accumulate on a "temporary counter." All of the balloons explode at a variable ratio (e.g., after 5 pumps or after 90 pumps). Each trial ends when the participant saves the accumulated points by pressing the enter key or when the balloon bursts and the participant loses the accumulated points for that trial. The dependent variable is the adjusted average number of pumps for unexploded balloons (Lejuez, Aklin, Zvolensky, \& Pedulla, 2003). Higher scores indicate greater risk taking.

\subsection{Time production task}

The TIME assesses disruptions in time perception, indicative of impulsivity (Dougherty, Mathias, \& Marsh, 2003). The rationale is that impulsive individuals experience the passage of time more slowly than non-impulsive individuals. The task consists of five trials, each beginning after the participant presses the left mouse button and ends when the participant considers that $1 \mathrm{~min}$ has passed and thus releases the button. The participant receives feedback at the end of each trial (i.e., how many seconds actually passed). The dependent variable is duration (in seconds) of each trial. Five pre-drink and five post-drink TIME scores were collected in the present study, one for each trial.

\subsection{Brief Biphasic Alcohol Effects Scale}

The B-BAES consists of six adjectives that describe three subjective sedative effects of alcohol (i.e., sedation, slower thinking, and slowed down) and three subjective stimulant effects of alcohol (i.e., more energetic, excited, and animated; Rueger, McNamara, \& King, 2009). Participants rate on a Likert scale $(0=$ "not at all" to $10=$ "extremely") how they feel at a given moment. In the present study, the scale showed good reliability and internal consistency $(\alpha=0.88-0.98)$ for both subscales at the four measurements.

\subsection{Heart rate}

The HR readings were derived from an ergometer (CardioVex EU13, Buenos Aires, Argentina) to calculate the average HR during the predrink baseline phase. This average was derived from the initial baseline assessment and from two assessments that were conducted during completion of the BART and TIME (see Fig. 1). During the treatment phase, HR was measured (see Fig. 1) during the actual consumption of alcohol or placebo (measurement 1 at experimental time $50 \mathrm{~min}$ ) and shortly after the drink was finished (measurement 2 at experimental time $65 \mathrm{~min}$ ). During the post-drink phase, HR was measured during completion of the BART (post-drink measurement 3, $80 \mathrm{~min}$ ) and during completion of the TIME (post-drink measurement 4, $110 \mathrm{~min}$ ).

\subsection{Data analysis}

Analysis of variance (ANOVA) indicated the absence of significant main effects of $\mathrm{FH}$ or Treatment and no significant $\mathrm{FH} \times$ Treatment interaction across the drinking indicators (see Table 1 for descriptive statistics). Therefore, drinking history was not a confounding factor in the present study. These analyses also indicated the absence of significant sex differences across most of the variables. Sex affected BBAES scores, with a significant main effect of sex $\left(F_{1,43}=5.65\right.$, $\left.p<0.05, \eta^{2} \mathrm{p}=0.12\right)$ and a significant sex $\times$ measure interaction $\left(F_{3,129}=7.69, p<0.001, \eta^{2} \mathrm{p}=0.15\right)$. Higher overall scores were found in women than in men, but this occurred independently of family history of alcohol problems, alcohol treatment, and B-BAES dimension. Therefore, the data for the subsequent analyses were collapsed across sex.

The ANOVAs also indicated that pre-drink scores (Table 2) were not significantly affected by $\mathrm{FH}$ or sex, with no $\mathrm{FH} \times$ sex interaction. Therefore, HR, TIME scores, and BART scores were calculated as a coefficient of change from pre-drink scores: Post-drink scores / (Pre-drink scores + Post-drink scores). A value of 0.5 indicates that the post-drink measurement was equal to the pre-drink measurement, whereas values higher and lower than 0.5 indicate an increase and decrease, 
respectively, in the magnitude of the post-drink measurement. The predrink HR value was the average of the three pre-drink HR measurements. The pre-drink TIME scores were those that were collected during each of the five trials of this task.

The coefficients of change in HR and TIME scores were independently analyzed using mixed ANOVAs, with $\mathrm{FH}(\mathrm{FH}+$ and $\mathrm{FH}-$ ) and treatment (alcohol and placebo) as between-subjects factors. These analyses included repeated measures (four within-measures for HR scores and five within-measures for Time scores, the latter corresponding to each of the trials). The relative change in the adjusted average number of pumps on the BART was assessed using a factorial ANOVA, with FH and treatment as between-subjects factors. B-BAES scores were analyzed using a mixed ANOVA, with treatment and $\mathrm{FH}$ as between-subjects factors and measurement $(1,2,3$, and 4) and dimension (positive and negative effects) as the repeated measures. BrAC measurements 1 to 4 were analyzed in the $\mathrm{FH}+$ and $\mathrm{FH}-$ groups using a mixed ANOVA.

Significant main effects and significant interactions were analyzed using Fisher's Least Significant Difference (LSD) test and planned comparisons. Fisher's LSD test was used to analyze significant main effects that involved between-subjects factors. Planned comparisons were mainly used to analyze significant between $\times$ within interactions. The rationale for using these tests was that there is no unambiguous choice of post hoc tests that involve between $\times$ within factors (Winer, Brown, \& Michels, 1991).

\section{Results}

\subsection{Breath alcohol concentration and heart rate}

The $\mathrm{FH}+$ and $\mathrm{FH}-$ groups exhibited similar and stable BrACs $(0.08 \% \pm 0.01 \%)$ across all measurements (all $p>0.05$; Fig. 2). The ANOVA of HR revealed a significant main effect of measurement $\left(F_{3.138}=3.29, p<0.05, \eta^{2} \mathrm{p}=0.07\right)$ and a significant $\mathrm{FH} \times$ treatment interaction $\left(F_{1,46}=7.18, p<0.05, \eta^{2} \mathrm{p}=0.15\right)$. The post hoc tests indicated that HR was significantly lower at measurement 3 than at measurements 1 and 2 . The post hoc tests also indicated that alcohol treatment significantly increased HR in the $\mathrm{FH}+$ group but did not alter $\mathrm{HR}$ in the $\mathrm{FH}-$ group. The $\mathrm{FH}+$ group that was given alcohol exhibited a significantly greater $\mathrm{HR}$ response than the $\mathrm{FH}+$ group that was given placebo and the $\mathrm{FH}$ - group that was given alcohol.

\subsection{Balloon analogue risk task}

Alcohol consumption increased risk-taking behavior on the BART compared with placebo. The ANOVA indicated a significant main effect of treatment $\left(F_{1,47}=4.26, p \leq 0.05, \eta^{2} p=0.09\right.$; Fig. 3$)$, with a nonsignificant trend toward a treatment $\times \mathrm{FH}$ interaction $\left(F_{1,47}=2.84\right.$, $p=0.09, \eta^{2} \mathrm{p}=0.06$ ). Based on our a priori hypotheses, we conducted planned comparisons within each FH group. These analyses revealed significantly higher risk taking in the $\mathrm{FH}+$ group that was given alcohol than in the $\mathrm{FH}+$ group that was given placebo, with no significant differences between $\mathrm{FH}$ - participants who were given alcohol and placebo.

\subsection{Time production task}

The ANOVA indicated no significant main effects or interactions. TIME scores in $\mathrm{FH}+$ and $\mathrm{FH}-$ participants were the following: $0.49 \pm 0.006$ and $0.49 \pm 0.005$ in the $\mathrm{FH}+$ groups (alcohol and placebo, respectively) and $0.50 \pm 0.007$ and $0.50 \pm 0.006$ in the $\mathrm{FH}-$ groups (alcohol and placebo, respectively).

\subsection{Brief Biphasic Alcohol Effects Scale}

The ANOVA indicated significant main effects of treatment
$\left(F_{1,47}=9.62, p \leq 0.001, \eta^{2} \mathrm{p}=0.17\right)$, measurement $\left(F_{3,141}=12.87\right.$, $\left.p \leq 0.001, \eta^{2} \mathrm{p}=0.21\right)$, and dimension $\left(F_{1,47}=8.72, p \leq 0.001\right.$, $\left.\eta^{2} \mathrm{p}=0.16\right)$ and significant $\mathrm{FH} \times$ treatment $\left(F_{1,47}=5.09, p \leq 0.05\right.$, $\left.\eta^{2} \mathrm{p}=0.10\right)$ and measure $\times$ treatment $\left(F_{3,141}=3.77, \quad p \leq 0.05\right.$, $\eta^{2} \mathrm{p}=0.07$ ) interactions (Fig. 4). Alcohol significantly increased BBAES scores, an effect that was exacerbated during measurement 1. Significantly greater perception of alcohol's effects was observed in the $\mathrm{FH}$ - group that was given alcohol than in the $\mathrm{FH}$ - group that was given placebo, with no significant differences between $\mathrm{FH}+$ participants who were given alcohol and placebo. The FH - group that was given placebo also scored significantly lower than the $\mathrm{FH}+$ groups that were given alcohol and placebo. The perception of negative effects was significantly greater than the perception of positive effects, but this occurred independently of treatment and FH.

\section{Discussion}

In the present study, alcohol exerted stimulatory effects and increased risk taking (measured by the BART) in young adults with a FH of alcohol abuse but not in control subjects with no FH of alcohol abuse. A novel aspect of the present study was that we used alcohol doses of 0.6 and $0.7 \mathrm{~g} / \mathrm{kg}$ for women and men, respectively, which yielded a BrAC of $0.08 \%$. These doses were lower than those used in related studies. Conrod et al. $(1997,2001)$ observed a significantly greater HR response in $\mathrm{FH}+$ subjects than in $\mathrm{FH}$ - subjects, but this effect was associated with a relatively high dose of alcohol $(1.0 \mathrm{ml} / \mathrm{kg})$ and BACs of approximately $0.12 \%$. One notable caveat of this previous study, however, was the lack of placebo control groups.

The psychomotor stimulant theory of addiction (Wise \& Bozarth, 1987) suggests that the potential of drugs of abuse to increase locomotion in rats is akin to the drug-induced elevation of HR in humans. Both responses are considered indicators of the appetitive motivational effect of the drug, which in turn promotes alcohol seeking and intake. In rats, alcohol doses that induce motor stimulation promote appetitive conditioned place preference (CPP), whereas doses that induce motor sedation do not produce CPP or produce conditioned place aversion (Pautassi, Nizhnikov, \& Spear, 2009). Moreover, adolescent rats exhibit alcohol-induced motor stimulation (Acevedo, Pautassi, Spear, \& Spear, 2013) and CPP, whereas adult rats exhibit alcohol-induced motor sedation and conditioned place aversion (Acevedo et al., 2013; Pautassi, Myers, Spear, Molina, \& Spear, 2008). Adolescent but not adult rats selfadministered sufficient alcohol to significantly increase HR (Ristuccia \& Spear, 2008). Participants who exhibited alcohol-induced elevations of $\mathrm{HR}$ also had a reward-seeking personality profile (Brunelle et al., 2004) and presented alcohol-induced aggression (Assaad et al., 2006).

The differentiator model (Newlin \& Thomson, 1990) combines the literature outlined in the preceding paragraph with the influential Low Level of Response Model (Schuckit, 2009). In subjects at risk for AUD, higher sensitivity to the stimulatory effects of alcohol coexists with lower sensitivity to the aversive and negative effects of alcohol. Congruent with this proposal, in the present study, $\mathrm{FH}+$ participants exhibited higher sensitivity to alcohol-induced HR stimulation and alcohol-induced risk taking compared with their FH - counterparts. FH + participants were also insensitive to the subjective effects of alcohol, which were predominantly negative and significantly observed in control, $\mathrm{FH}$ - participants.

These latter findings suggest that $\mathrm{FH}+$ participants may exhibit tolerance to the self-reported subjective perception of alcohol intoxication. This is only a preliminary hypothesis, however, and more work is needed to confirm our findings, which agree with some (Pilatti et al., 2014; Schuckit et al., 2004) but not all (Kerfoot et al., 2013; King, de Wit, McNamara, \& Cao, 2011) prior reports. Procedural differences, including the level of intoxication (e.g., BAC and BrAC) achieved, could be the source of these apparently disparate findings. Another important consideration is that these studies and the overwhelming majority of 

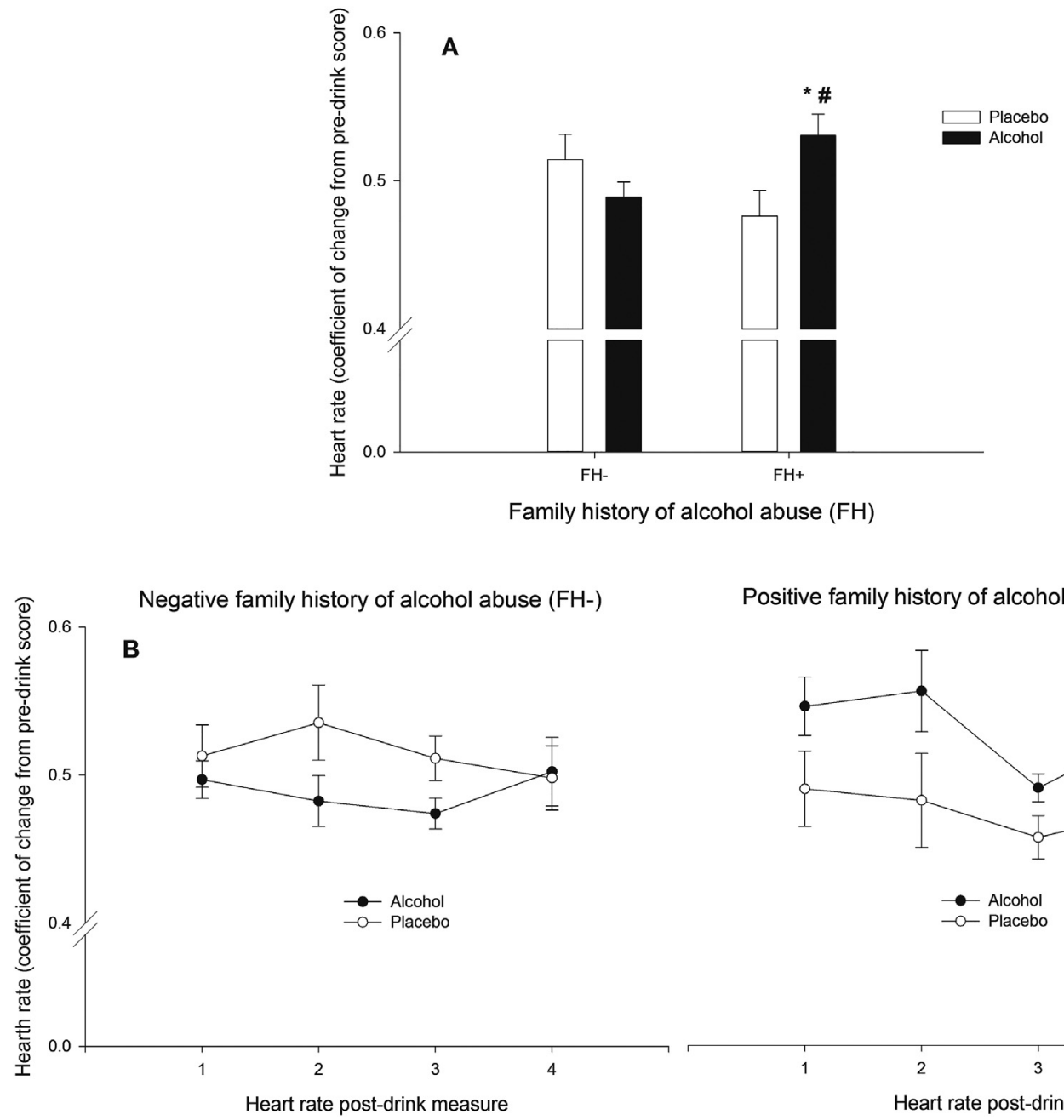

Positive family history of alcohol abuse $(\mathrm{FH}+)$

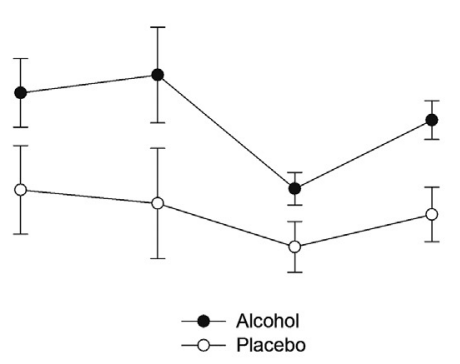

C

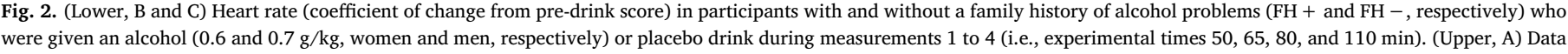

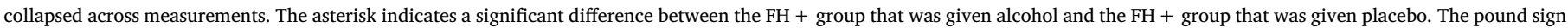
indicates a significant difference between the $\mathrm{FH}+$ group that was given alcohol and the $\mathrm{FH}-$ group that was given alcohol. The data are expressed as mean \pm SE.

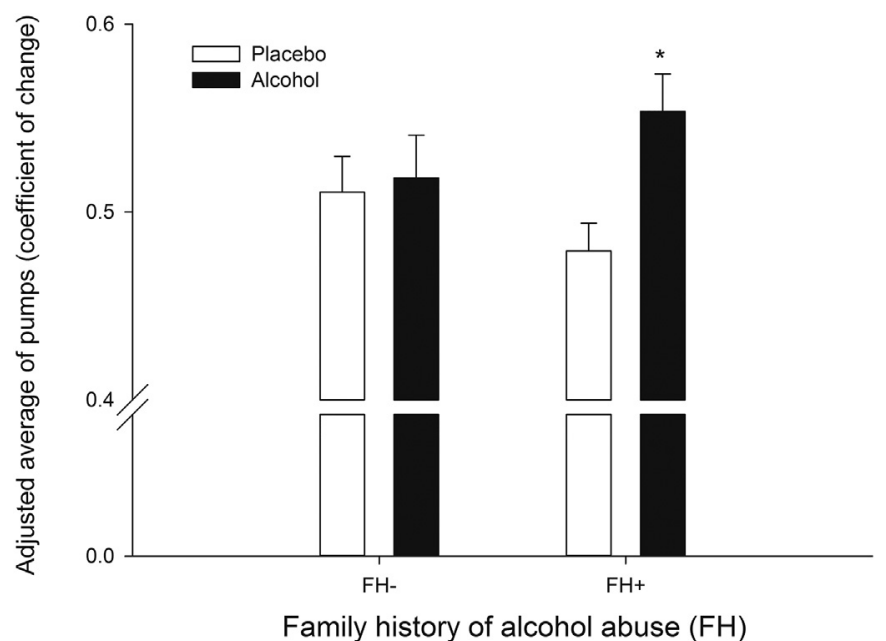

Fig. 3. Adjusted average number of pumps (coefficient of change from pre-drink phase) on the BART in participants with and without a family history of alcohol problems (FH + and $\mathrm{FH}-$, respectively) who were given an alcohol $(0.6$ and $0.7 \mathrm{~g} / \mathrm{kg}$, women and men, respectively) or placebo drink. The asterisk indicates a significant difference between the $\mathrm{FH}+$ group that was given alcohol and the $\mathrm{FH}+$ group that was given placebo. The data are expressed as mean $\pm \mathrm{SE}$. research in this area were conducted in North America. The influence of personality-related risk factors in this population may not apply to individuals with different cultural backgrounds. It is important to include a diverse array of geographical and cultural groups when analyzing psychological variables that are related to alcohol consumption (Henrich, Heine, \& Norenzayan, 2010). Tolerance can also be measured at different levels of analysis and either during the initial response to the drug or during later time-points of the BAC curve when adaptations (e.g., acute tolerance; Morzorati et al., 2002) can occur.

B-BAES scores were generally higher in $\mathrm{FH}+$ subjects than in $\mathrm{FH}-$ subjects, suggesting that $\mathrm{FH}+$ participants had an overall higher level of reactivity to the mild stress of the experiment. This is consistent with a study in which $\mathrm{FH}+$ participants reported significantly lower baseline levels of well-being and more distress than their FH - counterparts (Pilatti et al., 2016). An unexpected finding was that neither alcohol treatment nor FH influenced TIME scores. These null findings are similar to those found with the same task in social and heavy drinkers (Rose \& Grunsell, 2008) but contrast with previous studies that used different tasks and found significant increases in baseline motor impulsivity (Acheson et al., 2011) and a significantly lower impact of acute alcohol on motor impulsivity (Kareken et al., 2013) in $\mathrm{FH}+$ subjects compared with FH - subjects. Motor impulsivity but not the impulsivity process that is involved in time perception may be altered in $\mathrm{FH}+$ subjects. This possibility is consistent with the 

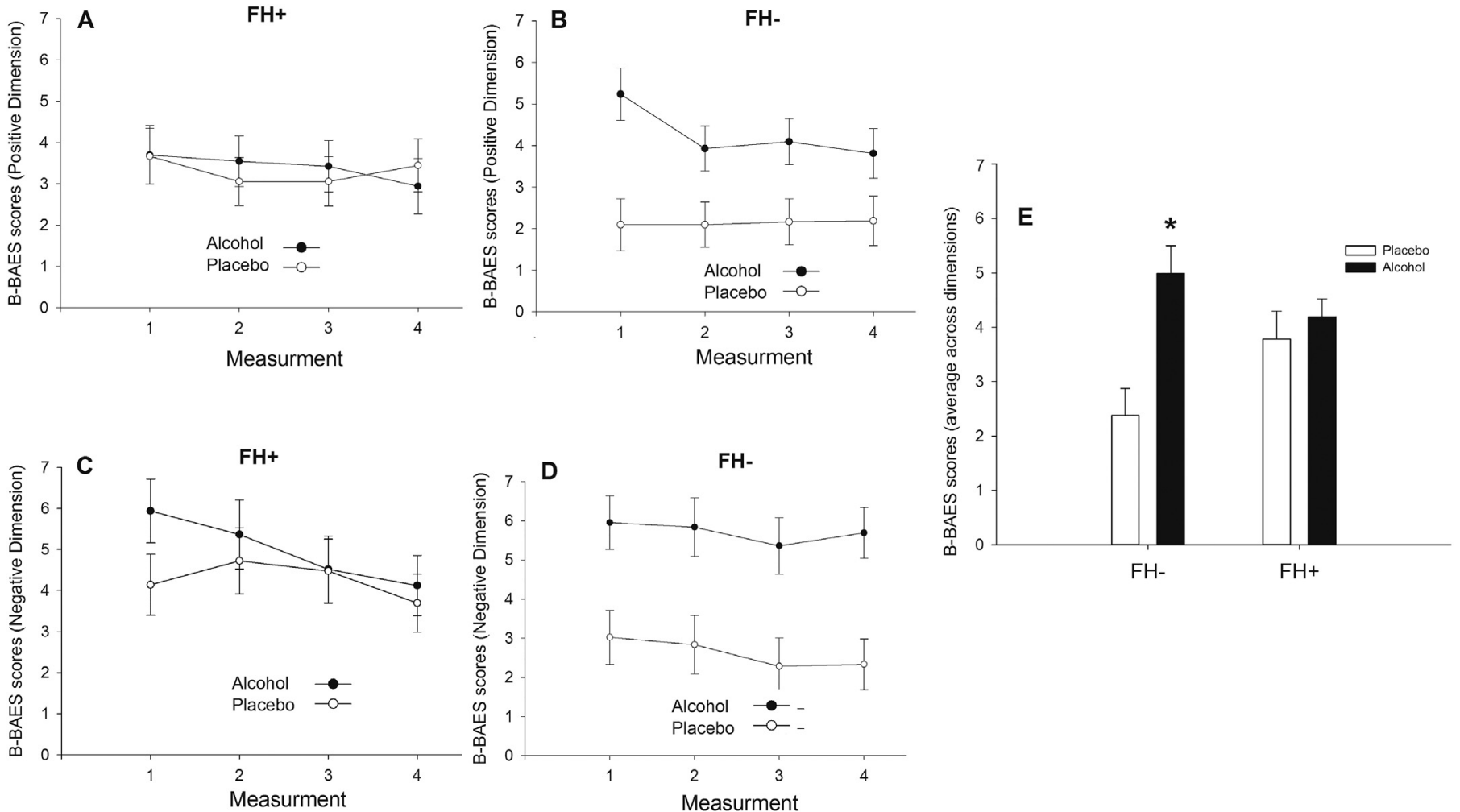

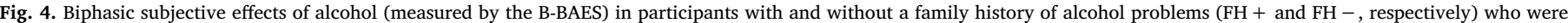

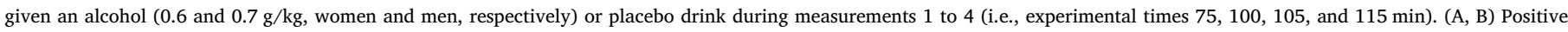

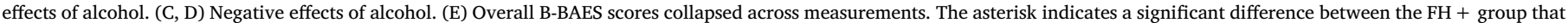

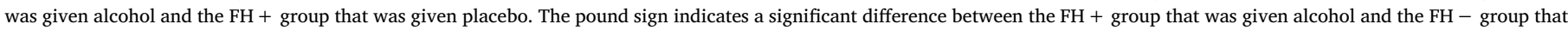
was given alcohol. The data are expressed as mean \pm SE.

multidimensional nature of impulsivity (de Wit, 2009) and suggests that time perception is less sensitive to acute alcohol intoxication than other impulsivity-related processes. Future studies should address these issues by including several alcohol doses and multiple measures of impulsivity.

Altogether, the present results support the hypothesis that $\mathrm{FH}+$ individuals exhibit greater sensitivity to the appetitive rewarding effects of alcohol and the augmenting effects of alcohol on risk taking compared with their $\mathrm{FH}-$ counterparts. $\mathrm{FH}+$ subjects exhibited blunted responsivity to the subjective effects of alcohol intoxication. At the theoretical level, these results corroborate the main tenets of the differentiator model (Newlin \& Thomson, 1990) and pinpoint the psychobiological mechanisms by which a positive $\mathrm{FH}$ of alcohol problems translates into a greater risk of AUD. This idiosyncratic pattern of response to the drug may be a pathway by which a FH of alcohol problems promotes alcohol drinking. At a more practical level, our findings suggest possible intervention strategies for individuals at risk for AUD.

\section{Role of funding source}

This work was supported by grants from the National Secretariat of Science and Technology (FonCyT) (No. PICT-2015-0849), from the Secretariat of Science and Technology - National University of Córdoba (SECyT-UNC) to AP and RMP. CONICET, FONCyT, and SECyT had no role in the study design, collection, analysis and interpretation of the data, writing the manuscript, or the decision to submit the paper for publication.

\section{Contributors}

A. Pilatti and R. Pautassi designed the study. F. Caneto collected the data and conducted the analysis. R. Pautassi reviewed the statistical analyses. F. Caneto and R. Pautassi prepared the first and subsequent versions of the manuscript. A. Pilatti provided critical reviews of the final version of the manuscript. All authors contributed to and have approved the final manuscript. All authors have read and approved the MS, believe that the paper represents honest work and are able to verify the validity of the statements reported.

\section{Conflict of interest}

All the authors declare that they have no conflicts of interest.

\section{Acknowledgements}

The authors would like to thank all the participants and to Francisco Tuzinkievich for his assistance during data collection.

\section{References}

Abroms, B. D., Gottlob, L. R., \& Fillmore, M. T. (2006). Alcohol effects on inhibitory control of attention: Distinguishing between intentional and automatic mechanisms. Psychopharmacology, 188(3), 324-334.

Acevedo, M. B., Pautassi, R. M., Spear, N. E., \& Spear, L. P. (2013). Age-dependent effects of stress on ethanol-induced motor activity in rats. Psychopharmacology, 230(3), 389-398.

Acheson, A., Richard, D. M., Mathias, C. W., \& Dougherty, D. M. (2011). Adults with a family history of alcohol related problems are more impulsive on measures of response initiation and response inhibition. Drug and Alcohol Dependence, 117(2), 198-203.

Assaad, J. M., Pihl, R. O., Séguin, J. R., Nagin, D. S., Vitaro, F., \& Tremblay, R. E. (2006) Intoxicated behavioral disinhibition and the heart rate response to alcohol. Experimental and Clinical Psychopharmacology, 14(3), 377.

Baumann, A. A., \& Odum, A. L. (2012). Impulsivity, risk taking, and timing. Behavioural Processes, 90(3), 408-414.

Brunelle, C., Assaad, J. M., Barrett, S. P., Ávila, C., Conrod, P. J., Tremblay, R. E., \& Pihl, R. O. (2004). Heightened heart rate response to alcohol intoxication is associated with a reward-seeking personality profile. Alcoholism: Clinical and Experimental 
Research, 28(3), 394-401.

Caswell, A. J., Morgan, M. J., \& Duka, T. (2013). Acute alcohol effects on subtypes of impulsivity and the role of alcohol-outcome expectancies. Psychopharmacology, 229(1), 21-30.

Conrod, P. J., Peterson, J. B., \& Pihl, R. O. (2001). Reliability and validity of alcoholinduced heart rate increase as a measure of sensitivity to the stimulant properties of alcohol. Psychopharmacology, 157, 20-30.

Conrod, P. J., Peterson, J. B., Pihl, R. O., \& Mankowski, S. (1997). Biphasic effects of alcohol on heart rate are influenced by alcoholic family history and rate of alcohol ingestion. Alcoholism: Clinical and Experimental Research, 21(1), 140-149.

Coskunpinar, A., Dir, A. L., \& Cyders, M. A. (2013). Multidimensionality in impulsivity and alcohol use: A meta-analysis using the UPPS model of impulsivity. Alcoholism: Clinical and Experimental Research, 37(9), 1441-1450.

Cronce, J. M., \& Corbin, W. R. (2010). Effects of alcohol and initial gambling outcomes on within-session gambling behavior. Experimental and Clinical Psychopharmacology, 18(2), 145.

Cyders, M. A., Zapolski, T. C., Combs, J. L., Settles, R. F., Fillmore, M. T., \& Smith, G. T. (2010). Experimental effect of positive urgency on negative outcomes from risk taking and on increased alcohol consumption. Psychology of Addictive Behaviors, 24(3), 367.

Dalley, J. W., Everitt, B. J., \& Robbins, T. W. (2011). Impulsivity, compulsivity, and topdown cognitive control. Neuron, 69(4), 680-694.

Dawson, D. A. (2000). The link between family history and early onset alcoholism: Earlier initiation of drinking or more rapid development of dependence? Journal of Studies on Alcohol, 61(5), 637-646.

Dougherty, D. M., Dew, R. E., Mathias, C. W., Marsh, D. M., Addicott, M. A., \& Barratt, E. S. (2007). Impulsive and premeditated subtypes of aggression in conduct disorder: Differences in time estimation. Aggressive Behavior, 33(6), 574-582.

Dougherty, D. M., Mathias, C. W., \& Marsh, D. M. (2003). Time paradigm (version 1.0) [manual]. Houston, Texas: Neurobehavioral Research Laboratory and Clinic, University of Texas Health Science Center at Houston.

George, S., Rogers, R. D., \& Duka, T. (2005). The acute effect of alcohol on decision making in social drinkers. Psychopharmacology, 182(1), 160-169.

Henrich, J., Heine, S. J., \& Norenzayan, A. (2010). The weirdest people in the world? Behavioral and Brain Sciences, 33, 1-75.

Herting, M. M., Schwartz, D., Mitchell, S. H., \& Nagel, B. J. (2010). Delay discounting behavior and white matter microstructure abnormalities in youth with a family history of alcoholism. Alcoholism: Clinical and Experimental Research, 34(9), 1590-1602.

Jenkins, M. B., Agrawal, A., Lynskey, M. T., Nelson, E. C., Madden, P. A., Bucholz, K. K., \& Heath, A. C. (2011). Correlates of alcohol abuse/dependence in early-onset alcoholusing women. The American Journal on Addictions, 20, 429-434.

Kareken, D. A., Dzemidzic, M., Wetherill, L., Eiler, W., II, Oberlin, B. G., Harezlak, J., ... O'Connor, S. J. (2013). Family history of alcoholism interacts with alcohol to affect brain regions involved in behavioral inhibition. Psychopharmacology, 228(2), 335-345.

Kerfoot, K., Pittman, B., Ralevski, E., Limoncelli, D., Koretski, J., Newcomb, J., ... Petrakis, I. L. (2013). Effects of family history of alcohol dependence on the subjective response to alcohol using the intravenous alcohol clamp. Alcoholism: Clinical and Experimental Research, 37(12), 2011-2018.

King, A. C., de Wit, H., McNamara, P. J., \& Cao, D. (2011). Rewarding, stimulant, and sedative alcohol responses and relationship to future binge drinking. Archives of General Psychiatry, 68(4), 389-399.

LaBrie, J. W., Migliuri, S., Kenney, S. R., \& Lac, A. (2010). Family history of alcohol abuse associated with problematic drinking among college students. Addictive Behaviors, 35, $721-725$.

Lejuez, C. W., Aklin, W., Daughters, S., Zvolensky, M., Kahler, C., \& Gwadz, M. (2007) Reliability and validity of the youth version of the Balloon Analogue Risk Task (BART-Y) in the assessment of risk-taking behavior among inner-city adolescents. Journal of Clinical Child and Adolescent Psychology, 36(1), 106-111.

Lejuez, C. W., Aklin, W. M., Zvolensky, M. J., \& Pedulla, C. M. (2003). Evaluation of the Balloon Analogue Risk Task (BART) as a predictor of adolescent real-world risktaking behaviours. Journal of Adolescence, 26(4), 475-479.

Morzorati, S. L., Ramchandani, V. A., Flury, L., Li, T. K., \& O'Connor, S. (2002). Selfreported subjective perception of intoxication reflects family history of alcoholism when breath alcohol levels are constant. Alcoholism: Clinical and Experimental Research, 26(8), 1299-1306.

Newlin, D. B., \& Thomson, J. B. (1990). Alcohol challenge with sons of alcoholics: A critical review and analysis. Psychological Bulletin, 108(3), 383.
Pautassi, R. M., Godoy, J. C., \& Molina, J. C. (2015). Adolescent rats are resistant to the development of ethanol-induced chronic tolerance and ethanol-induced conditioned aversion. Pharmacology Biochemistry and Behavior, 138, 58-69.

Pautassi, R. M., Myers, M., Spear, L. P., Molina, J. C., \& Spear, N. E. (2008). Adolescent but not adult rats exhibit ethanol-mediated appetitive second-order conditioning. Alcoholism: Clinical and Experimental Research, 32(11), 2016-2027.

Pautassi, R. M., Nizhnikov, M. E., \& Spear, N. E. (2009). Assessing appetitive, aversive, and negative ethanol-mediated reinforcement through an immature rat model. Neuroscience \& Biobehavioral Reviews, 33(6), 953-974.

Pilatti, A., Caneto, F., Garimaldi, J. A., Vera, B.d. V., \& Pautassi, R. M. (2014). Contribution of time of drinking onset and family history of alcohol problems in alcohol and drug use behaviors in Argentinean college students. Alcohol and Alcoholism, 49(2), 128-137.

Pilatti, A., Fernández, C., Viola, A., García, J. S., \& Pautassi, R. M. (2017). Efecto reciproco de impulsividad y consumo de alcohol en adolescentes argentinos. Salud y drogas, 17(1).

Pilatti, A., Montejano, G. R., Cesar, A., Bertone, M. F. H., Cumin, G., \& Pautassi, R. M. (2016). Efecto del estrés social agudo sobre impulsividad, toma de riesgos y sesgos atencionales en jóvenes con y sin historia familiar de abuso de alcohol. Suma Psicológica. Available online November, 3rd 2016 http://dx.doi.org/10.1016/j. sumpsi.2016.09.003.

Potenza, M., \& de Wit, H. (2010). Control yourself: Alcohol and impulsivity. Alcoholism: Clinical and Experimental Research, 34, 1303-1318.

Quinn, P. D., \& Fromme, K. (2011). Subjective response to alcohol challenge: A quantitative review. Alcoholism: Clinical and Experimental Research, 35(10), 1759-1770.

Ristuccia, R. C., \& Spear, L. P. (2008). Adolescent and adult heart rate responses to selfadministered ethanol. Alcoholism: Clinical and Experimental Research, 32(10), $1807-1815$.

Rose, A. K., \& Duka, T. (2008). Effects of alcohol on inhibitory processes. Behavioural Pharmacology, 19(4), 284-291.

Rose, A. K., \& Grunsell, L. (2008). The subjective, rather than the disinhibiting, effects of alcohol are related to binge drinking. Alcoholism: Clinical and Experimental Research, 32(6), 1096-1104.

Rubia, K., Halari, R., Christakou, A., \& Taylor, E. (2009). Impulsiveness as a timing disturbance: Neurocognitive abnormalities in attention-deficit hyperactivity disorder during temporal processes and normalization with methylphenidate. Philosophical Transactions of the Royal Society of London B: Biological Sciences, 364(1525), 1919-1931.

Rueger, S. Y., McNamara, P. J., \& King, A. C. (2009). Expanding the utility of the Biphasic Alcohol Effects Scale (BAES) and initial psychometric support for the Brief-BAES (BBAES). Alcoholism: Clinical and Experimental Research, 33(5), 916-924.

Schrieks, I. C., Stafleu, A., Kallen, V. L., Grootjen, M., Witkamp, R. F., \& Hendriks, H. F. (2014). The biphasic effects of moderate alcohol consumption with a meal on ambiance-induced mood and autonomic nervous system balance: A randomized crossover trial. PLoS One, 9(1), e86199. http://dx.doi.org/10.1371/journal.pone.0086199 (Jan 21).

Schuckit, M. A. (1985). Ethanol-induced changes in body sway in men at high alcoholism risk. Archives of General Psychiatry, 42(4), 375-379.

Schuckit, M. A. (2009). An overview of genetic influences in alcoholism. Journal of Substance Abuse Treatment, 36(1), S5-14.

Schuckit, M. A., \& Gold, E. O. (1988). A simultaneous evaluation of multiple markers of ethanol/placebo challenges in sons of alcoholics and controls. Archives of General Psychiatry, 45(3), 211-216.

Schuckit, M. A., Smith, T. L., \& Kalmijn, J. (2004). The search for genes contributing to the low level of response to alcohol: Patterns of findings across studies. Alcoholism: Clinical and Experimental Research, 28(10), 1449-1458.

Schuckit, M. A., Smith, T. L., Kalmijn, J., Tsuang, J., Hesselbrock, V., \& Bucholz, K. (2000). Response to alcohol in daughters of alcoholics: A pilot study and a comparison with sons of alcoholics. Alcohol and Alcoholism, 35(3), 242-248.

Smith, G. T., Fischer, S., Cyders, M. A., Annus, A. M., Spillane, N. S., \& McCarthy, D. M. (2007). On the validity and utility of discriminating among impulsivity-like traits. Assessment, 14(2), 155-170.

Winer, B., Brown, D. R., \& Michels, K. M. (1991). Statistical principles in experimental de sign. New York: McGraw-Hill.

Wise, R. A., \& Bozarth, M. A. (1987). A psychomotor stimulant theory of addiction. Psychological Review, 94(4), 469.

de Wit, H. (2009). Impulsivity as a determinant and consequence of drug use: A review of underlying processes. Addiction Biology, 14, 22-31. 